\title{
NATURA: CARBONO NEUTRO
}

\section{Patrícia Berardi}

Escola de Administração de Empresas de São Paulo, Fundação Getulio Vargas

\section{Mario Prestes Monzoni Neto}

Escola de Administração de Empresas de São Paulo, Fundação Getulio Vargas

Chegando a sua sala, o Gerente de Impacto Ambiental da Natura recebe a convocação para as reuniões do Comitê de Sustentabilidade e do Comitê Estratégico para primeira semana de fevereiro de 2007. A data se aproxima e ele terá que decidir: apoiar o prosseguimento do projeto carbono neutro ou abortá-lo. Sua posição poderá mudar a gestão da empresa.

\section{A empresa}

A Natura é uma empresa brasileira que, desde 1969, atua no setor de cosméticos, com principal atividade definida em cosméticos, fragrâncias e higiene pessoal. Tem como princípio básico, a preocupação com a natureza, já que a essência de seus produtos está diretamente a ela vinculada.

A visão de negócio da companhia estabelece uma estreita relação na busca por uma harmonia individual, entre a comunidade e com a natureza. Estabelece que a razão de ser da empresa é criar e comercializar produtos e serviços que promovam o Bem-estar e o Estar-bem.

Seu portfólio contempla uma vasta gama de produtos, com mais de 700 itens nas categorias de maquiagem, perfumaria, proteção solar, cabelo, corpo, entre outras. Baseada em 6 diferentes localidades do Brasil, concentra sua maior parte operacional e logística no município de Cajamar, em São Paulo. Uma das principais características de distribuição e venda de seus produtos no Brasil se dá

\section{CFGV-EAESP/RAE 2010}

Todos os direitos reservados. Permitida a citação parcial, desde que identificada a fonte. Proibida a reprodução total. Em caso de dúvidas, consulte a Redação: gvcasos.redacao@fgv.br; (11) 3799-3717 
por venda direta por meio de consultores, como são assim denominados, em 5 mil municípios, abarcando cerca de 50 milhões de consumidores. Adicionalmente, a empresa opera em outros países da América Latina, sendo: Argentina, Chile, Peru, México, Venezuela e Colômbia, além de atuar junto ao mercado francês. Na venda por canal direto, a Natura compete primordialmente com a Avon, que opera em grande escala no Brasil e em toda a América Latina. Existem, contudo, concorrentes em segmentos específicos, tais como:

- $\quad$ Fragrâncias: Avon e O Boticário

- $\quad$ Produtos para cuidado do corpo e da pele: Avon, Beiersdorf AG (fabricante da Nivea e outros produtos), L'Oréal S.A., Unilever N.V. e Monange

- $\quad$ Produtos para cuidado dos cabelos: Unilever N.V., L'Oréal S.A., Colgate-Palmolive Company e Johnson \& Johnson

- $\quad$ Maquilagem: Avon, O Boticário.

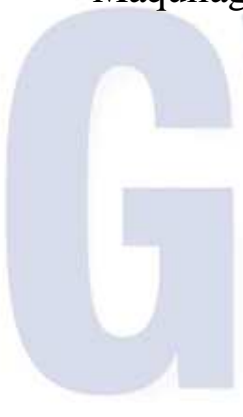

\begin{tabular}{lc}
\hline \multicolumn{1}{c}{ Consultoras } & $\mathbf{2 0 0 8}$ \\
\hline Brasil & 730.600 \\
Arg., Chile, Peru & 90.000 \\
Méx., Vem., Colômbia & 28.200 \\
\hline
\end{tabular}

Tabela 1: total de consultoras em 2008

Fonte: Comentário Desempenho (website), acesso em 28/02/2009

Em diversos momentos de sua história, a empresa posiciona a geração dos negócios com as premissas de desenvolvimento sustentável, em que busca o equilíbrio econômico, ambiental e social: introduziu, em 1983, o uso de refil nas embalagens; substituiu, em 1997, a frota de veículos utilizados no município de São Paulo por gás natural; implementou, em 2003, a estação de tratamento de efluentes com sistema aeróbio; substitui, em 2005, a utilização de gordura animal por óleos de origem vegetal em uma das linhas de produtos; e nos últimos anos desenvolve diversas ações com interesse na busca pela sustentabilidade, dentre elas: a utilização de energia solar; a troca de matérias-primas por produtos orgânicos, uso de material reciclado em embalagens. 
A empresa destaca-se em diversas categorias, dentre elas governança corporativa, marca, clima organizacional, sustentabilidade e já obteve diversos reconhecimentos e prêmios, a saber:

- Melhor Empresa do Setor Farmacêutico, Higiene e Limpeza - 2004 e 2005, Revista Istoé Dinheiro.

- Melhor Empresa do Ano no Setor de Produtos Químicos - 2005 e 2006 EXCELÊNCIA EMPRESARIAL - Fundação Getúlio Vargas.

- $\quad$ MELHORES E MAIORES - Revista Exame: Higiene, Beleza e Cosmético - 2006.

- $\quad$ Melhor Empresa do Setor Farmacêutico, Higiene e Cosméticos - 2004.

- Melhor Empresa do Setor Farmacêutico, Higiene e Limpeza - 2004 e 2005, Revista Istoé Dinheiro.

- $\quad$ GUIA EXAME DE BOA CIDADANIA - Revista Exame e Instituto Ethos: Classificada entre as 10 empresas referência.

- VALOR 1000 - Jornal Valor Econômico: Melhor Empresa do Setor de Higiene e Cosméticos 2005 e 2006.

- IR Magazine Brazil Awards - IR Magazine:

- Melhor Governança Corporativa - 2006 e 2007.

- Melhor Sustentabilidade Socioambiental - 2007.

- Grand Prix do Melhor Programa de Relações com Investidores (empresas fora do Ibovespa), 2005.

- Melhor Desempenho em Relações com Investidores numa Oferta Pública Inicial (IPO) -2005 .

A relação completa dos prêmios e reconhecimentos da Natura pode ser consultada no website da empresa.

\section{Estrutura Organizacional}

A Natura possui um Conselho de Administração, composto por 7 membros e a Diretoria Estatutária é formada por 4 diretores. Por estabelecimento do Conselho de Administração, existem Comitês com atribuições específicas: 
- $\quad$ Comitê de Auditoria e Gestão de Riscos e de Finanças

- $\quad$ Comitê de Pessoas e Organização

- $\quad$ Comitê Estratégico

- $\quad$ Comitê de Governança Corporativa.

- $\quad$ Comitê de Sustentabilidade

Todos estes comitês têm como principais atribuições subsidiar o Conselho de Administração na tomada de decisões estratégicas, políticas e normativas, além de acompanhar e monitorar a implantação das diretrizes estabelecidas.

O acompanhamento e tomada das decisões estratégias corporativas sobre Mudanças Climáticas é realizado no Comitê da Sustentabilidade, que se reúne mensalmente e é composto pela Presidência, Vice-Presidência de Operações Brasil e Diretorias de Sustentabilidade, Desenvolvimento e Assuntos Corporativos, englobando assim, esferas e áreas multidisciplinares.

\section{Natura em números}

Empresa fora constituída inicialmente, como empresa de capital fechado. Em 2004, decidiu abrir capital e fazer emissão de ações na bolsa de valores para possibilitar novos investimentos de capital via mercado acionário e passou assim a trabalhar segundo regras específicas que regem tais transações, mediante as normas do Novo Mercado ${ }^{1}$. Num total de 429 milhões de ações, 73,42\% permanecem em poder dos controladores.

Numa análise de evolução de seus papéis, verifica-se uma variação positiva de $213 \%$ nas suas ações frente uma variação de $99 \%$ do índice base do mercado brasileiro (Ibovespa), para o período desde o início das transações das ações até final de 2008 (website acesso em 01 de março de 2009).

\footnotetext{
${ }^{1}$ O Novo Mercado é um segmento de listagem destinado à negociação de ações emitidas por companhias que se comprometam, voluntariamente, com a adoção de práticas de governança corporativa adicionais, em relação ao que é exigido pela legislação. É a exigência de que o capital social da companhia seja composto somente por ações ordinárias.
} 
Na Tabela 2 são apresentadas as principais rubricas dos demonstrativos financeiros consolidados da empresa nos últimos dois anos. Os números mostram um aumento de receita, de lucro, de investimentos, ocorreu boa redução dos empréstimos de curto prazo, embora o total de empréstimos não se constitua em parcela relevante das contas.

\begin{tabular}{lrr}
\hline Descrição & \multicolumn{1}{c}{$\mathbf{2 0 0 8}$} & \multicolumn{1}{c}{$\mathbf{2 0 0 7}$} \\
\hline R Mil & \multicolumn{1}{c}{$\mathbf{\text { M Mil }}$} \\
\hline Total de Ativos & $1.732 .917,00$ & $1.556 .917,00$ \\
Ativo Circulante & $759.742,00$ & $701.112,00$ \\
Clientes & $428.421,00$ & $512.094,00$ \\
Investimento & $864.142,00$ & $766.439,00$ \\
Passivo Circulante & $802.457,00$ & $707.212,00$ \\
Empréstimo CP & $5.293,00$ & $120.785,00$ \\
Dividendos & $311.854,00$ & $237.898,00$ \\
Dívida Coligadas & $250.555,00$ & $145.037,00$ \\
Empréstimo LP & $177.972,00$ & $116.847,00$ \\
Patrim ônio Líquido & $711.175,00$ & $684.121,00$ \\
Receita Líquida & $3.168 .000,00$ & $2.619 .936,00$ \\
Lucro Líquido & $542.200,00$ & $446.230,00$ \\
\hline
\end{tabular}

Tabela 2: Números da Natura (consolidado)

Fonte: Relatório Anual 2007 e website da empresa (acesso em 06/03/2009)

\section{Conhecendo as emissões de Carbono}

No ano de 2005, a empresa iniciou, após a criação da Diretoria de Sustentabilidade, uma reflexão com relação ao tema do aquecimento global. Num primeiro momento, o objetivo era entender como tal assunto poderia influenciar os negócios, ou melhor, como a empresa poderia ser avaliada pelo contexto de contribuições ao fato do mundo estar em processo de rápidas mudanças e adicionalmente visualizar o papel de cada agente como contribuinte desse processo.

Ainda sem caráter estratégico e sem conhecer propriamente a dimensão de seus impactos com relação às emissões de Gases de Efeito Estufa (GEE), a discussão e a investigação por maiores informações seguiram na área de sustentabilidade da empresa, ao longo do ano de 2006. Como as questões referentes aos temas de desenvolvimento sustentável permeiam todas as áreas da Natura numa forma transversal e estão realmente inseridas no contexto dos negócios, a área de sustentabilidade 
procura captar tendências no mundo todo, em diferentes segmentos de mercado, para buscar um melhor entendimento para embasar suas atividades, dentro da filosofia de postura diferenciada quanto aos negócios e o meio ambiente.

Uma vez tendo tomado conhecimento do problema do aquecimento global, a empresa contratou uma consultoria, que orientou e definiu uma linha de investigação das emissões dos GEE nas atividades da Natura, o que, entre outras consequências, gerou um Position Paper apresentado ao mercado sobre as expectativas e postura da empresa.

Uma das primeiras iniciativas geradas em 2006, por meio de orientação da consultoria, adicionalmente ao planejamento da área de sustentabilidade, foi a criação da rede interna de levantamento de GEE, composta por colaboradores de diversas áreas, nomeado de Sistema Natura de Gases de Efeito Estufa. Após a capacitação da equipe, composta por 10 profissionais de 6 diferentes áreas, o objetivo principal era levantar e conhecer as emissões diretas da produção. Esse projeto foi custeado pela Diretoria de Sustentabilidade.

O resultado do estudo trouxe informações importantes, porém de caráter básico, o que indicava não demonstrar toda a profundidade e complexidade que o assunto demandava. Neste momento, diversos questionamentos foram imputados ao projeto. Seria suficiente abordar apenas o escopo de produção? As emissões indiretas seriam relevantes no levantamento? Qual a real responsabilidade da empresa no processo de emissão dos GEE ao longo da cadeia? Qual o peso dessas respostas para a atividade da empresa?

As principais dúvidas foram suscitadas pelo responsável da área de inovação, que insistia em apontar que a responsabilidade da empresa, como em toda a indústria de cosméticos, está bastante inserida na geração indireta das emissões e dos respectivos impactos da cadeia produtiva, desde a extração da matéria-prima até o final do processo logístico. O ponto central das discussões estava na definição do escopo de avaliação que seria adotado pela Natura. Segundo as classificações sugeridas pelo Programa de Emissões de Gases (nome oficial em inglês é Greenhouse Gas Protocol, GHG Protocol) - que fornece diretrizes para o inventário das emissões, os três diferentes níveis de emissão de GEE são: Escopo 1 avalia as emissões diretas, ou seja, ligada ao processo produtivo; Escopo 2 
contabiliza as emissões indiretas de energia elétrica e Escopo 3 foca o levantamento das emissões indiretas decorrentes das operações da empresa mas não controladas por ela. A descrição completa encontra-se no Anexo I.

Esses questionamentos tiveram impacto no planejamento estratégico da Natura, e a dúvida pairava se o projeto em questão estava plenamente alinhado com o objetivo maior de trilhar a sustentabilidade, em todas as suas atividades e relações de negócio.

O gerente de impacto ambiental, em conjunto com outros profissionais da empresa, estressaram as discussões em busca de possibilidades para verificar o real impacto dos negócios da Natura em relação ao meio ambiente. Principalmente, na questão da responsabilidade e na definição do escopo a ser utilizado para os levantamentos dos dados. Não só a definição do escopo do inventário demandou um esforço intenso dos profissionais envolvidos no projeto como o segundo estágio, que foi a orientação e conclusão por que recursos utilizar no levantamento, consumiu várias horas de conversas e reuniões. Durante esta etapa, foram suscitas algumas alternativas até que a equipe concluiu por realizar o inventário das emissões de GEE segundo a análise do ciclo de vida do produto (ACV). Esta decisão constitui-se como um dos grandes desafios enfrentados pelo projeto.

A ACV é uma importante ferramenta de gestão ambiental que possibilita verificar o potencial impacto ao meio ambiente a partir do uso de recursos e materiais e suas respectivas transformações ao longo da cadeia até a disposição final do produto. Com essa ferramenta, se avaliada de forma criteriosa e cuidadosa, pode-se contabilizar em todo o processo produtivo a geração de resíduos e as emissões de gases de efeito estufa, apresentando uma grande fonte de informações preciosas.

Assim, traduz-se em valioso recurso para tomadas de decisões operacionais e estratégicas pois pode-se avaliar que materiais processar, como reduzir determinadas utilizações de insumos, buscar eficiência não só no uso mas também na logística, transportes, armazenagem, pensar alternativas de materiais e processos, buscar e desenvolver novas tecnologias, inovação de produtos ou parte deles, entre tantas outras.

O mapeamento apresentado no Anexo II demonstra claramente onde estão os principais contribuintes ao processo de emissão dos GEE em todo o processo da cadeia. Por este diagrama ficou 
evidenciado que os diferentes enquadramentos dos escopos da metodologia influenciam sobremaneira as implicações e responsabilizações. Pelo Escopo 1, o levantamento indicou 3\% de emissões, no Escopo 2, apenas 1\% de emissão enquanto que o Escopo 3 totaliza $96 \%$ das emissões do processo produtivo.

Desta forma, após o levantamento de representação dos processos emissores de GEE, tanto diretos como indiretos, foi possível atestar o nível de contribuição de cada etapa da cadeia produtiva, permitindo assim, embasar as tomadas de decisões e definições das responsabilidades e o grau de abrangência que a empresa poderia adotar.

O caminho percorrido pela empresa, desde o início das primeiras investigações até as conclusões finais para possibilitar a definição estratégica foram:

Etapa 1 - inventário, em 2006, pela metodologia do GHG Protocol. Nesta fase já surgiram diferentes entendimentos, levando a questionamentos de proporções relevantes para a estratégia de negócio da empresa, com diferentes discussões sobre qual o real impacto causado pela atividade da Natura e como a empresa deveria se posicionar frente a tais responsabilidades. Avaliar apenas impactos diretos (Escopo 1) ou rastrear todas as fases operacionais diretas e indiretas (Escopo 3).

Etapa 2 - definida a ampliação do escopo de análise para processos diretos e indiretos, chegando-se a um total de 179,6 mil toneladas de $\mathrm{CO}_{2}$ tendo como base o ano de 2006 e de 183,6 mil toneladas de $\mathrm{CO}_{2}$ para o ano de 2007.

Num primeiro passo a decisão tomada foi de identificar, dentre o processo produtivo, quais os itens de maior peso e impacto nas emissões, estabelecendo-se o mapeamento para três matériasprimas e três materiais de embalagem, por representarem $65 \%$ do volume total consumido em 2007 pela empresa.

O passo seguinte foi mapear e identificar todas as matérias-primas e materiais de embalagem pela análise de ciclo de vida, permitindo assim, não só conhecer as emissões de $\mathrm{CO}_{2}$, mas também analisar a viabilidade de desenvolver processos e produtos considerados mais limpos, ou seja, menos impactantes. 
Etapa 3 - com os dados coletados, foi então permitido que os profissionais envolvidos no grupo de trabalho emitissem seus pareceres e sugerissem, com melhor grau de conhecimento sobre as atividades da empresa e as respectivas emissões de GEE, quais deveriam ser as próximas etapas do planejamento estratégico, a fim de subsidiar a definição do Comitê de Sustentabilidade e do Conselho Administrativo.

\section{Propostas de atuação.}

Nesse momento, diversas alternativas e possibilidades deveriam ser consideradas a exaustão, com os mais variados cenários e projeções. Uma proposta seria abortar todo o processo e propor a manutenção da atuação da empresa pelos moldes ora utilizados. Outra seria estudar possibilidades de redução de emissão apenas da produção direta, com riscos, entre outros, de ter sua imagem contestada pela limitação de responsabilidade além de potencialmente afetar sua fonte de recursos no longo-prazo com perdas a biodiversidade, escassez e altos custos de água e energia. Ou ainda, pensar na redução das emissões diretas e atuar em parceria nas emissões indiretas, que no caso da Natura, pode ser considerada como moderadamente geradora de emissões de GEE já que 96\% das emissões está na cadeia sob forma indireta, estabelecendo prazos e metas para matérias-primas, materiais de embalagem, fornecedores diretos, transporte e descarte de produtos.

Uma alternativa mais ousada, no entanto, poderia ser a sugestão de não só reduzir as emissões de toda a cadeia, mas adicionalmente, neutralizar e compensar as emissões que não forem passíveis de redução. Esta talvez fosse a proposta mais complexa e difícil, que demandaria muito mais planejamento, investimento, dedicação, inovação e mudanças nos processos de negócio da empresa. Uma possibilidade plausível seria apenas adentrar no mercado de créditos de carbono, em que simplesmente a empresa não teria necessidades de alterar seus processos, e sim, negociar a troca de suas emissões em mercados regulamentados, como tantas ouras empresas já fazem.

Dentre as alternativas, qual deveria ser a sugestão a ser levada aos comitês, considerando todos os riscos e oportunidades para a Natura? 


\section{Anexo I - GHG Protocol}

\section{Escopo 1: Emissões diretas de GEE}

Emissões diretas de GEE são as provenientes de fontes que pertencem ou são controladas pela empresa, como por exemplo as emissões de combustão em caldeiras, fornos, veículos da empresa ou por ela controlados, emissões da produção de químicos em equipamentos de processos que pertencem ou são controlados pela empresa, entre outros.

As emissões diretas de $\mathrm{CO}_{2}$ resultantes da combustão de biomassa não deverão ser incluídas no Escopo 1, mas sim comunicadas separadamente. As emissões de GEE que não estejam cobertas pelo Protocolo de Quioto, como por exemplo CFCs, NOx, etc., não deverão ser incluídas no Escopo 1 mas podem ser comunicadas em separado.

\section{Escopo 2: Emissões indiretas de GEE de eletricidade}

O Escopo 2 contabiliza as emissões de GEE provenientes da aquisição de eletricidade que é consumida pela empresa. A eletricidade adquirida é definida como sendo aquela que é comprada ou então trazida para dentro dos limites organizacionais da empresa. No Escopo 2 as emissões ocorrem fisicamente no local onde a eletricidade é gerada.

\section{Escopo 3: Outras emissões indiretas de GEE}

O Escopo 3 é uma categoria opcional de relatório, que permite a abordagem de todas as outras emissões indiretas. As emissões do Escopo 3 são uma conseqüência das atividades da empresa, mas ocorrem em fontes que não pertencem ou não são controladas pela empresa.

Alguns exemplos de atividades de Escopo 3 são a extração e produção de matérias-primas e outros materiais utilizados nos processos da empresa, aquisição e transporte de combustíveis e a venda de produtos e serviços. 
Os participantes do Programa Brasileiro GHG Protocol devem contabilizar e elaborar os Escopos 1 e 2 de maneira independente. Emissões do Escopo 1 devem ser subdivididas nas quatro categorias abaixo:

- Combustão estacionária para geração de eletricidade, vapor, calor ou energia usando equipamento em um local fixo;

- Combustão móvel de combustíveis em fontes de transporte e equipamentos fora-deestrada tais como os usados em construção, agricultura e florestas;

- Processos físicos e químicos que não sejam combustão, tais como a produção de cimento, alumínio, ácido adípico e amônia; e

- Fontes fugitivas, ou seja, liberações não intencionais da produção, processamento, transmissão, armazenagem e uso de combustíveis e outras substâncias que não passem por chaminés, drenos, tubos de escape ou outra abertura funcionalmente equivalente, tais como liberação de hexafluoreto de enxofre em equipamentos elétricos, hidrofluorcarbonos durante o uso de equipamento de refrigeração e ar condicionado e vazamento de metano no transporte de gás natural.

Emissões de Escopo 3 que contribuem significativamente para o total de emissões da empresa participante do Programa devem também ser incluídas no relatório. Em particular:

- Participantes do setor de serviços devem incluir no relatório emissões de Escopo 3 resultantes de viagens de negócios e transporte de funcionários;

- Participantes do setor de cimentos devem incluir no relatório emissões de Escopo 3 da compra de clinker;

- Todos os participantes devem incluir no relatório as emissões de Escopo 3 que sejam parte de protocolos específicos em seus setores. 


\section{Anexo II - Mapa de emissões}
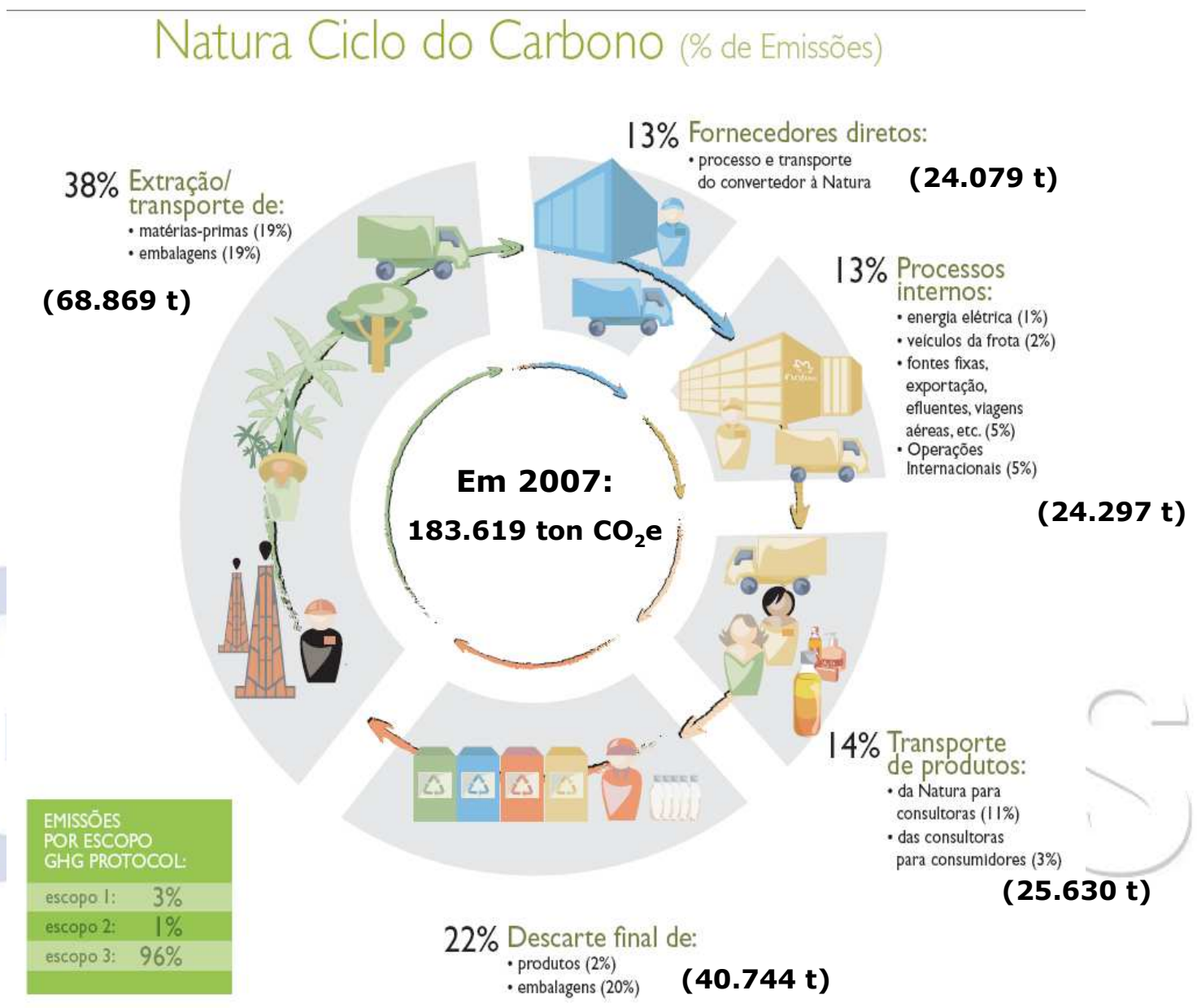